Open Access

\title{
Alcohol consumption, endogenous estrogen and mammographic density among premenopausal women
}

Hanne Frydenberg ${ }^{1 *}$, Vidar G. Flote ${ }^{1}$, Ine M. Larsson ${ }^{1}$, Emily S. Barrett ${ }^{2}$, Anne-Sofie Furberg ${ }^{3}$, Giske Ursin ${ }^{4}$, Tom Wilsgaard ${ }^{3}$, Peter T. Ellison ${ }^{5}$, Anne McTiernan ${ }^{6}$, Anette Hjartåker ${ }^{7}$, Grazyna Jasienska ${ }^{8}$ and Inger Thune ${ }^{1,3}$

\begin{abstract}
Introduction: Alcohol consumption may promote aromatization of androgens to estrogens, which may partly explain the observations linking alcohol consumption to higher breast cancer risk. Whether alcohol consumption is associated with endogenous estrogen levels, and mammographic density phenotypes in premenopausal women remains unclear.

Methods: Alcohol consumption was collected by self-report and interview, using semi quantitative food frequency questionnaires, and a food diary during seven days of a menstrual cycle among 202 premenopausal women, participating in the Energy Balance and Breast Cancer Aspects (EBBA) study I. Estrogen was assessed in serum and daily in saliva across an entire menstrual cycle. Computer-assisted mammographic density (Madena) was obtained from digitized mammograms taken between days 7-12 of the menstrual cycle. Multivariable regression models were used to investigate the associations between alcohol consumption, endogenous estrogen and mammographic density phenotypes.

Results: Current alcohol consumption was positively associated with endogenous estrogen, and absolute mammographic density. We observed $18 \%$ higher mean salivary $17 \beta$-estradiol levels throughout the menstrual cycle, among women who consumed more than $10 \mathrm{~g}$ of alcohol per day compared to women who consumed less than $10 \mathrm{~g}$ of alcohol per day $(p=0.034)$. Long-term and past-year alcohol consumption was positively associated with mammographic density. We observed a positive association between alcohol consumption (past year) and absolute mammographic density; high alcohol consumers ( $\geq 7$ drinks/week) had a mean absolute mammographic density of $46.17 \mathrm{~cm}^{2}$ (95\% confidence interval (CI) 39.39, 52.95), while low alcohol consumers ( $<1$ drink/week) had a mean absolute mammographic density of $31.26 \mathrm{~cm}^{2}(95 \% \mathrm{Cl} 25.89,36.64)$ (p-trend 0.001). After adjustments, high consumers of alcohol ( $\geq 7$ drinks/week), had 5.08 (95\% Cl 1.82, 14.20) times higher odds of having absolute mammographic density above median $\left(>32.4 \mathrm{~cm}^{2}\right)$, compared to low $(<1$ drink/week) alcohol consumers.
\end{abstract}

Conclusion: Alcohol consumption was positively associated with daily endogenous estrogen levels and mammographic density in premenopausal women. These associations could point to an important area of breast cancer prevention.

\footnotetext{
* Correspondence: hanne.frydenberg@medisin.uio.no

${ }^{1}$ The Cancer Centre, Oslo University Hospital, 0424 Oslo, Norway

Full list of author information is available at the end of the article
}

\section{Biomed Central}

(c) 2015 Frydenberg et al. Open Access This article is distributed under the terms of the Creative Commons Attribution 4.0 International License (http://creativecommons.org/licenses/by/4.0), which permits unrestricted use, distribution, and reproduction in any medium, provided you give appropriate credit to the original author(s) and the source, provide a link to the Creative Commons license, and indicate if changes were made. The Creative Commons Public Domain Dedication waiver (http://creativecommons.org/publicdomain/zero/1.0/) applies to the data made available in this article, unless otherwise stated. 


\section{Introduction}

High alcohol consumption has consistently been associated with breast cancer development [1-5], while a positive association between alcohol consumption and mammographic density, a strong independent biomarker for breast cancer development [6], has been observed in some studies [7-9], but not all [10]. In addition, few studies have included current and long-term alcohol consumption when studying the association between alcohol consumption and breast cancer risk [11]. Thus, whether there is an association between alcohol consumption and mammographic density phenotypes among premenopausal women remains unclear [12-14].

A positive association between endogenous estrogen and breast cancer development has consistently been observed $[15,16]$. Interestingly, alcohol consumption may interfere with estrogen pathways, by influencing both aromatase activity, and therefore estrogen concentrations, and estrogen receptors [17-19]. Moreover, alcohol consumption may also interfere with the menstrual cycle by reducing variability and decreasing frequency of long cycles $[20,21]$. Recently, high alcohol consumption was associated with endogenous luteal estrogen levels [22], and elevated weekend consumption of alcohol has been associated with higher peak levels of estrogens [3, 23]. Thus, one of the possible hypotheses suggested to explain the role of alcohol in breast cancer development is through its effect on the cumulative level of endogenous estrogen throughout life.

Importantly, assessment of endogenous sex steroid hormones among premenopausal women is complicated by intercyclic and intracyclic variations [24], but intercyclic variations seem to be less marked in nonseasonal and industrial populations [25]. Thus, given the substantial intracycle amplitude in hormone levels, at least 7-8 days/cycle should be measured but one cycle seems to be a valid measurement in regularly cycling women in a westernized society $[24,25]$. Only a few studies have observed the association between endogenous estrogens levels and current and long-term alcohol consumption using both food diary and food frequency questionnaires (FFQ) in premenopausal women, and much remains unclear $[22,26]$. Moreover, the association between alcohol consumption in combination with daily cyclic endogenous hormones and mammographic density phenotypes among premenopausal women remains unclear.

Recently, we observed a positive association between daily sex steroid hormones, growth factors, and mammographic density phenotypes $[27,28]$, while we previously have observed endogenous estrogen to be associated with important breast cancer risk factors including age at menarche and body composition [29-31]. These observations support the hypothesis that several lifestyle-related breast cancer risk factors might exert their effect on breast cancer development through sex steroid hormones.

On the basis of biological mechanisms suggested, and given that alcohol intake is a modifiable lifestyle factor and much remains unclear regarding the association between alcohol intake, endogenous estrogen, and mammographic density, there is a need for additional studies. The main aim of the present study was thus to examine the association between current, past-year, and longterm alcohol consumption, endogenous estrogen levels, and mammographic density phenotypes among premenopausal women.

\section{Methods}

\section{Subjects and study design}

A total of 204 women, aged 25-35 years, participated in the Norwegian Energy Balance and Breast Cancer Aspects I (EBBA-I) study during 2000-2002 at the Department of Clinical Research, University Hospital of North Norway (UNN), Tromsø [29]. Women were recruited from the general population by announcements in local newspapers and in public meeting places. Study subjects had to meet the following criteria, which were checked both in a telephone interview and in a personal interview by the same trained nurse during the entire study period: self-reported regular menstruation (cycle length: 22-38 days within the previous 3 months), no use of steroid contraceptives, pregnancy or lactation in the previous 6 months, no infertility, no history of gynecological disorders, and no chronic disorders (e.g. diabetes, hypothyroidism/hyperthyroidism) [29]. All women were fasting when attending three subsequent study visits throughout one menstrual cycle starting on the first day of menstrual bleeding: first visit, days 1-5 of the menstrual cycle (early follicular phase); second visit, days 7-12 (late follicular phase); and third visit, days 2125 (late luteal phase). Two women were excluded owing to missing mammographic data, resulting in 202 women being included in the present study.

\section{Clinical examination and lifestyle factors}

The participants underwent clinical examination at three scheduled visits by the same physicians. First attendance was on the first possible day after onset of menstrual bleeding at the Clinical Research Center, UNN, Tromsø, Norway. Height was measured to the nearest $0.5 \mathrm{~cm}$, and weight to the nearest $0.1 \mathrm{~kg}$ on an electronic scale, body mass index (BMI) was calculated (in $\mathrm{kg} / \mathrm{m}^{2}$ ), and waist circumference was measured [29]. Validated questionnaires (self-administered and interviewer administered) were used to collect information about reproductive history, previous hormone use, diet, and lifestyle factors [29, 31]. 


\section{Assessment of alcohol consumption}

Alcohol consumption was assessed using a validated precoded food diary (Department of Nutrition, University of Oslo, Norway) and semi-quantitative FFQ. The food diary captured current alcohol consumption during seven selected days, representing each day of 1 week during the menstrual cycle (days 3-6 of the follicular phase and days 21-23 of the luteal phase) [32]. The semi-quantitative FFQ captured long-term alcohol consumption across the lifespan and alcohol consumption during the past year: "Have you ever drunk alcohol (yes/no)? If yes, how many glasses of wine, $1 / 2$ liters of beer, fortified wine $(0.4 \mathrm{dl})$ or measures of spirits did you drink on average per month at the following ages? (15-19 years, 20-24 years, 25-34 years)." "Are you currently an abstainer (yes/no)? If no, how many measures of alcohol have you consumed on average per month or per week in the past 12 months?" Both assessment methods were obtained by self-report, and were later checked for inconsistencies and missing values by trained interviewers.

\section{Assessment of estrogen}

Overnight fasting serum concentrations of estrogen were assessed in fresh serum samples, taken at the three visits. The serum concentration of $17 \beta$-estradiol was measured using a direct immunometric assay (Immuno-1; Bayer Diagnostics UNN, Tromsø, Norway), and analyzed (Department of Clinical Chemistry, UNN, Tromsø, Norway). The sensitivity for estradiol was $0.01 \mathrm{nmol} / \mathrm{l}$ and the coefficient of variation $(\mathrm{CV})$ was $3.9 \%$.

The participants collected daily morning saliva samples throughout one menstrual cycle, starting the first day of menstrual bleeding [33]. Collection of saliva in plastic tubes, pretreated with sodium azide, was done according to previously established validated protocols developed at the Reproductive Ecology Laboratory at Harvard University, Cambridge, MA, USA and the manufacturer's protocol (Diagnostic Systems Laboratory, Webster, TX, USA) [33, 34]. The 17 $\beta$-estradiol concentrations were measured in daily saliva samples using a ${ }^{125}$ I-based radioimmunoassay kit (\#39100; Diagnostic Systems Laboratory, Webster, TX, USA). The samples were stored at $-70{ }^{\circ} \mathrm{C}$. All samples were run in duplicate, and samples from the same cycles were run within the same assay. The assays were carried out in different batches.

All cycles were aligned to the day of ovulation based on the identification of the drop in17 $\beta$-estradiol, which provides a reasonable estimate of the day of ovulation $[33,35]$. The mid-cycle $17 \beta$-estradiol drop could not be made for 14 of the participants: eight participants had too many missing days mid cycle, making it impossible to determine a drop day; and six participants had no discernible rise or drop in estradiol during the critical time window, and thus their cycles were unable to be aligned. These 14 women were therefore excluded from further analysis. The overall mean salivary $17 \beta$-estradiol concentration was calculated for all 204 women, whereas midmenstrual $17 \beta$-estradiol (days -7 to +6 ) indices were calculated for the 190 women with aligned cycles. The sensitivity of the $17 \beta$-estradiol assay was $4 \mathrm{pmol} / \mathrm{l}$, and average intra-assay variability was $9 \%$. The measurements of $17 \beta$-estradiol had higher CVs at the start and end of the menstrual cycle, and the interassay variability ranged from $23 \%$ (low pool) to $13 \%$ (high pool). Furthermore, there were higher rates of missing data at the end of the cycle, and thus we included $17 \beta$-estradiol salivary aligned measurements from day -7 to day +6 in this study.

\section{Assessment of mammographic density phenotypes}

Bilateral two-view mammograms were obtained in the study from all women between cycle days 7 and 12 at the Centre of Breast Imaging, UNN, Troms $\varnothing$, Norway using a standard protocol [36]. The left craniocaudal mammograms were digitized, and imported into a computerized mammographic density assessment program (Madena; University of Southern California School of Medicine, Los Angeles, CA, USA) [37]. One trained reader conducted the density measurements. The total breast area was defined using a special outlining tool, and the Madena software estimated size (in $\mathrm{cm}^{2}$ ) of this area. In order to assess density, the reader outlined a region of interest (ROI), and applied a tinting tool to pixels considered to represent dense areas of the mammograms within the ROI. The Madena software calculated the size of this dense area (in $\mathrm{cm}^{2}$ ). Absolute mammographic breast density represented this dense area, and percent mammographic density was the ratio of absolute mammographic breast density to total breast area. The mammograms were read in four batches, with an equal number of mammograms in each batch. A duplicate reading of 26 randomly selected mammograms from two of the batches showed an intraclass correlation coefficient for reliability of 0.94 .

\section{Statistical analysis}

Based on plausible suggested mechanisms linking alcohol to endogenous estrogen and to mammographic density, we studied the association between current and past alcohol intake alone, and in combination with endogenous estrogen levels and the study outcomes-percent and absolute mammographic density-using multivariate regression models. Previous observations in premenopausal [38] and postmenopausal [39] women have observed a twofold to threefold increase in breast cancer risk for women with percent mammographic density above $25 \%$. These observations support the comparison of women with above versus below median percent mammographic 
density. Mammographic density outcome variables were thus used as both continuous and dichotomized variables, representing lower and higher density using median values as cutoff points: percent mammographic density ( $28.5 \%)$, and absolute mammographic density $\left(32.4 \mathrm{~cm}^{2}\right)$.

All variables, except alcohol consumption, were approximately normally distributed, allowing data analysis by parametric tests. Alcohol consumption was somewhat skewed and log transformation was performed prior to linear regression analysis; thus, the log transformation did not influence our results and the results are presented on the original scale. In addition, we logtransformed the hormone data owing to outliers; the results, however, were not influenced and the results are presented on the original scale.

Descriptive characteristics are presented as mean (standard deviation) or percent (number). Equality between categories of alcohol consumption was tested using one-way analysis of variance for continuous variables, and the chi-square test for binary variables. Based on suggested biological mechanisms influencing mammographic density, regression models including several potentially confounding variables were fitted. We tested whether adjustments for potentially confounding factors such as age (continuous), BMI (continuous), age at menarche (continuous), number of children (continuous), previous oral contraceptive (OR) use (categorical), current smoking habits (categorical), energy intake (continuous), and leisure-time activity (continuous) influenced our estimates. Age (continuous), BMI (continuous), number of children (continuous), current smoking habits (categorical), and previous OC use (categorical) were included as covariates in the final models. In regression models, alcohol consumption was considered both as a continuous variable and as a categorical variable, and the $p$-trend value was calculated based on continuous variables. Long-term alcohol consumption was defined as the average consumption from age 15 to present, and divided into categories: never/rarely, 1-4 drinks/month, and $>1$ drinks/week. Glasses of alcoholic beverages (past year and current) reported in both the FFQ and the food diary was converted into grams of alcohol by applying definitions of standard drinks for each beverage. Past year alcohol consumption was then divided into categories: total alcohol consumption ( $<1$ drinks/week, 1-6 drinks/ week, $\geq 7$ drinks/week), and beer/wine/spirits consumption in past year ( $<1$ drinks/week, $\geq 1$ drink/week). Current alcohol consumption was defined as average consumption over 7 days and was divided in two categories: $<1 \mathrm{drink} /$ day and $\geq 1 \mathrm{drink} /$ day. We defined one alcoholic drink as $10 \mathrm{~g}$ alcohol, which corresponds to about a small bottle $(330 \mathrm{ml})$ of beer with $3.2 \mathrm{~g}$ alcohol per $100 \mathrm{ml}$, one glass $(125 \mathrm{ml})$ of wine with $8.8 \mathrm{~g}$ alcohol per $100 \mathrm{ml}$, or a small glass $(23 \mathrm{ml})$ of spirits with $31.7 \mathrm{~g}$ per $100 \mathrm{ml}$.
In the logistic regression models, alcohol consumption during the past year was used as a categorical variable, and the median split of mammographic density phenotypes was used as the dependent variable. One model was adjusted for age, and a multivariable model was further adjusted for BMI, number of children, current smoking habits, and previous $\mathrm{OC}$ use.

Multivariable adjusted, linear, mixed models for repeated measures were used to examine variation in daily salivary $17 \beta$-estradiol across the menstrual cycle, according to low ( $<1$ drink/day) and high ( $\geq 1$ drink/day) levels of current alcohol consumption. In addition, we stratified the analyses by median split of absolute mammographic density $\left(32.4 \mathrm{~cm}^{2}\right)$. The Toeplitz covariance structure was used in all models.

All statistical tests were two-sided using a significance level of $p<0.05$. Statistical analyses were conducted with SPSS version 21.0 (IBM Corporation, Armonk, NY, USA).

\section{Ethical consideration}

All of the participating women signed an informed consent form, including taking a mammogram. The study protocol was reviewed and approved by the Regional Committee for Medical Research Ethics Northern Norway and the Norwegian Data Inspectorate (reference: 2001/ 36768 and 11).

\section{Results}

Characteristics of the study population are presented in Table 1 . Women who were high alcohol consumers $(\geq 7$ drinks/week, past year) tended to be younger, of older age at menarche, and had fewer children compared with low alcohol consumers ( $<1 \mathrm{drink} /$ week, past year). Alcohol consumption in the past year was positively associated with both percent mammographic density and absolute mammographic density (Table 1 ). There was a moderate positive correlation between current and pastyear alcohol consumption (Additional file 1).

After adjustments, we observed an association between alcohol consumption in the past year and absolute mammographic density. High alcohol consumers $(\geq 7$ drinks/week) over the past year had a $47.6 \%$ higher mean absolute mammographic density compared with low alcohol consumers ( $<1$ drinks/week) over the past year $\left(46.2 \mathrm{~cm}^{2}(95 \%\right.$ CI $39.4,53.0)$ vs. $31.3 \mathrm{~cm}^{2}(95 \% \mathrm{CI}$ $25.9,36.6)$ ( $p$-trend 0.001$)$ ). The same positive association was observed with long-term alcohol use and absolute mammographic density ( $p$-trend $=0.029)($ Table 2$)$.

In multivariable linear regression analyses, we calculated estimated change in mammographic density per unit increase in the alcohol intake variable. Alcohol consumption in the past year was associated with both percent mammographic density ( $\beta$-value $0.7,95 \% \mathrm{CI}$ 
Table 1 Characteristics of the study population by alcohol consumption (drinks/week) in the past year (FFQ), Norwegian EBBA-I study $(n=202)^{a}$

\begin{tabular}{|c|c|c|c|c|c|}
\hline Variable & Overall $(n=202)^{\mathrm{a}}$ & $\begin{array}{l}\text { Low consumers } \\
(<1 \text { drink/week })(n=66)^{\mathrm{a}}\end{array}$ & $\begin{array}{l}\text { Moderate consumers } \\
(1-6 \text { drinks/week })(n=96)^{\mathrm{a}}\end{array}$ & $\begin{array}{l}\text { High consumers } \\
\left(\geq 7 \text { drinks/week) }(n=40)^{a}\right.\end{array}$ & $p$ value $^{k}$ \\
\hline \multicolumn{6}{|l|}{ Characteristics } \\
\hline Age (years) & $30.7(3.07)$ & $31.17(2.86)$ & $30.75(3.16)$ & $29.87(3.09)$ & 0.105 \\
\hline Education (years) & $16.1(3.02)$ & $15.82(2.85)$ & $15.98(3.04)$ & $16.70(3.20)$ & 0.324 \\
\hline \multicolumn{6}{|l|}{ Reproductive history } \\
\hline Age at menarche (years) & $13.1(1.36)$ & $12.75(1.29)$ & $13.21(1.36)$ & $13.48(1.36)$ & 0.016 \\
\hline Cycle length (days) & $28.2(3.17)$ & $28.40(4.13)$ & $28.01(2.78)$ & $28.98(3.5)$ & 0.314 \\
\hline Parous (\%) & 51.2 & 61.2 & 46.0 & 27.5 & 0.002 \\
\hline Number of children $(n)$ & $0.91(1.13)$ & $1.30(1.29)$ & $0.80(0.98)$ & $0.53(0.99)$ & 0.001 \\
\hline \multicolumn{6}{|l|}{ Anthropometric measures ${ }^{c}$} \\
\hline $\mathrm{BMI}\left(\mathrm{kg} / \mathrm{m}^{2}\right)$ & $24.4(3.77)$ & $24.47(2.30)$ & $24.55(3.56)$ & $23.92(3.35)$ & 0.665 \\
\hline Waist (cm) & $79.5(9.80)$ & $76.69(11.26)$ & $80.28(9.56)$ & $77.44(7.47)$ & 0.300 \\
\hline \multicolumn{6}{|l|}{ Lifestyle factors } \\
\hline Leisure time (MET/hour/week) & $57.6(88.6)$ & 48.09 (33.44) & $63.23(121.18)$ & $59.59(45.16)$ & 0.552 \\
\hline \multicolumn{6}{|l|}{ Oral contraceptive use } \\
\hline Previous use (\%) & 82.7 & 76.1 & 85.0 & 90.0 & 0.119 \\
\hline Sum use (years) & $3.7(3.7)$ & $3.27(3.72)$ & 3.99 (3.69) & $3.84(3.63)$ & 0.458 \\
\hline \multicolumn{6}{|l|}{ Alcohol consumption in the past year } \\
\hline Alcohol (drinks/week) & $3.46(4.10)$ & $0.24(0.28)$ & $2.67(1.46)$ & $10.84(2.87)$ & $<0.001$ \\
\hline Abstainers (\%) & 6.8 & & & & \\
\hline \multicolumn{6}{|l|}{ Smoking habits } \\
\hline Current smokers (\%) & 22.1 & 11.9 & 25.0 & 32.5 & 0.030 \\
\hline Former smokers (\%) & 45.4 & 32.8 & 50.0 & 55.0 & 0.037 \\
\hline \multicolumn{6}{|l|}{ Serum hormones $^{d}$} \\
\hline Estradiol (pmol/l) & $146.7(61.6)$ & $145.5(70.49)$ & $147.4(62.80)$ & $146.8(41.04)$ & 0.983 \\
\hline \multicolumn{6}{|l|}{ Salivary hormones } \\
\hline Estradiol, overall average ${ }^{e}(\mathrm{pmol} / \mathrm{l})$ & 17.9 (8.79) & $17.68(7.65)$ & $17.61(9.29)$ & $18.98(9.40)$ & 0.691 \\
\hline Estradiol, mid-menstrual ${ }^{f}(\mathrm{pmol} / \mathrm{l})$ & $18.20(8.98)$ & $17.69(7.52)$ & $18.05(9.69)$ & $19.01(9.59)$ & 0.839 \\
\hline \multicolumn{6}{|l|}{ Mammograms ${ }^{g}$} \\
\hline Percent mammographic density (\%) & $29.8(19.0)$ & $28.08(19.05)$ & $27.33(18.02)$ & $38.51(19.30)$ & 0.005 \\
\hline Absolute mammographic density $\left(\mathrm{cm}^{2}\right)$ & $34.7(23.4)$ & $31.57(21.00)$ & $31.89(22.73)$ & $46.77(25.23)$ & 0.001 \\
\hline
\end{tabular}

Data presented as mean (standard deviation). One drink or unit is equal to $10 \mathrm{~g}$ alcohol

$B M I$ body mass index, EBBA-I Norwegian Energy Balance and Breast Cancer Aspects I, FFQ food frequency questionnaire, MET metabolic equivalents

${ }^{a}$ Numbers may vary owing to missing information

${ }^{b}$ Equality between levels were tested using one-way analysis of variation for continuous variables and the chi-square test for binary variables

cMeasurements at days 1-5 after onset of menstrual cycle

${ }^{d}$ Serum samples in early follicular phase: days $1-5$ after onset of menstrual cycle

eDaily saliva samples throughout an entire menstrual cycle

fDaily saliva samples mid menstrual cycle, aligned cycle days -7 to 6

${ }^{9}$ Mammograms were taken days 7-12 (mid-cycle phase)

$0.2,1.2)$ and absolute mammographic density ( $\beta$-value 1.3, 95 \% CI 0.5, 2.0). Similar associations were apparent, when past-year alcohol consumption was analyzed by alcohol type; for example, wine, beer, and others (Table 3). No association was observed between total current alcohol consumption and percent or absolute mammographic density (Table 3 ).
In age-adjusted logistic regression analyses, women with high alcohol consumption ( $\geq 7$ drinks/week) had 2.4 (95 \% CI 1.0, 5.6) and 4.4 (95 \% CI 1.8, 10.9) higher odds of having high (above median) percent and absolute mammographic density, compared with women who were low ( $<1$ drink/week) alcohol consumers. Similarly, in multivariable models we observed, among high 
Table 2 Multivariable adjusted means of mammographic density measures by alcohol consumption by long-term, past-year, and current consumption in premenopausal women $(n=202)^{a}$

\begin{tabular}{|c|c|c|c|}
\hline Alcohol consumption ${ }^{b}$ & Number & Percent density (\%) & Absolute density $\left(\mathrm{cm}^{2}\right)$ \\
\hline \multicolumn{4}{|l|}{ Long-term, average $^{c}$} \\
\hline Never/rarely & 7 & $32.14(21.44,42.84)$ & $36.66(20.17,53.15)$ \\
\hline 1-4 drinks/month & 134 & $26.74(24.30,29.17)$ & $31.02(27.27,34.77)$ \\
\hline$>1$ drinks/week & 43 & $33.67(29.27,38.11)$ & $42.08(35.27,48.89)$ \\
\hline$p$-linear trend & & 0.051 & 0.029 \\
\hline \multicolumn{4}{|l|}{ Past year, average ${ }^{d}$} \\
\hline$<1$ drinks/week & 66 & $28.71(25.23,32.20)$ & $31.26(25.89,36.64)$ \\
\hline 1-6 drinks/week & 95 & $27.52(24.73,30.31)$ & $32.17(27.87,36.48)$ \\
\hline$\geq 7$ drinks/week & 40 & $36.42(32.02,40.83)$ & $46.17(39.39,52.95)$ \\
\hline$p$-linear trend & & 0.003 & 0.001 \\
\hline \multicolumn{4}{|l|}{ Current, past week $^{\mathrm{e}}$} \\
\hline$<1$ drink/day & 143 & $28.11(25.79,30.42)$ & $33.08(29.46,36.69)$ \\
\hline$\geq 1 \mathrm{drink} /$ day & 58 & $33.57(29.87,37.28)$ & $40.38(32.78,44.35)$ \\
\hline p-difference & & 0.016 & 0.121 \\
\hline
\end{tabular}

Data presented as mean (95\% confidence interval). All analyses have used multivariate linear models

FFQ food frequency questionnaire

Adjusted for age (continuous), body mass index (continuous), number of children (continuous), previous oral contraceptives (categorical), and current smokers (categorical)

${ }^{a}$ Numbers may vary owing to missing information

${ }^{\mathrm{b}}$ One drink or unit is equal to $10 \mathrm{~g}$ alcohol

${ }^{c}$ Alcohol consumption reported from age 15 to present time, FFQ

${ }^{\mathrm{d}}$ Alcohol consumption reported in past year, FFQ

${ }^{\mathrm{e}}$ Alcohol consumption reported in last 7 days representing 1 week, food diary

consumers of alcohol, 5.1 (95\% CI 1.8, 14.2) times higher odds of having absolute mammographic density above median compared with low consumers. When we examined the type of alcohol consumed, high consumers ( $\geq 2$ drinks/week) of wine had statistically significant 2.5 times higher odds ratio of having absolute mammographic density above the median, compared with low consumers ( $<2$ drinks/week) of wine. However, our sample size was limited regarding the type of beverages (Table 4).

We found that women who consumed more than one unit of alcohol per day had $18 \%$ higher mean salivary $17 \beta$-estradiol levels across the menstrual cycle compared with women who consumed less than one unit of alcohol per day ( $p=0.034)$ (Fig. 1a). In analyses stratified by median absolute mammographic density, we observed that women with high current alcohol consumption $(>1$ drink/day) and high absolute mammographic density $\left(>32.4 \mathrm{~cm}^{2}\right)$ had $28 \%$ higher mean salivary $17 \beta$-estradiol levels throughout the menstrual cycle, compared with women who consumed less than one unit of alcohol per day $(p=0.033)$ (Fig. 1c). No association was observed between current alcohol consumption and salivary $17 \beta$ estradiol in women with low absolute mammographic density $\left(\leq 32.4 \mathrm{~cm}^{2}\right)$ (Fig. 1b). Moreover, no associations were observed between alcohol consumption, salivary estrogen, and percent mammographic density. Of note, no associations were observed between alcohol consumption, serum estrogen, and mammographic density phenotypes (data not shown). To test for interaction between alcohol consumption and mammographic density, variables were first dichotomized and then entered into the linear mixed model with interaction terms. We observed no statistically significant interactions between alcohol consumption and mammographic density (data not shown).

\section{Discussion}

In this study among premenopausal women, we observed positive associations between current alcohol consumption and endogenous estrogen levels, as women who reported consuming $>10 \mathrm{~g}$ alcohol per day during the last week had $18 \%$ higher mean $17 \beta$-estradiol level throughout the menstrual cycle compared with women who consumed $<10 \mathrm{~g}$ alcohol per day during the last week. We also observed positive associations between past-year and long-term alcohol intake and percent and absolute mammographic density. Women who reported drinking $\geq 7$ drinks/week over the past year had $48 \%$ higher absolute mammographic density, compared with low alcohol consumers ( $<1$ drinks/week). Similarly, high alcohol consumers in the past year had five times higher odds ratio of having above-median absolute mammographic density compared with low alcohol consumers during the past year. Of note, the current average alcohol consumption in our study was low, with a mean alcohol consumption of 2.9 drinks per week, and $18 \%$ reported drinking more than one drink of alcohol per day (mean $6.7 \mathrm{~g}$ alcohol/day). Of note, the women reported drinking on average $11.3 \mathrm{~g}$ alcohol at weekends and on average $2.5 \mathrm{~g}$ alcohol per day on weekdays, which corresponds with levels of alcohol consumption observed in comparable populations [10]. Furthermore, we observed similar alcohol consumption by the two assessment methods used (semi-quantitative FFQ and food diary).

Owing to the limited number of participants included, and the limited variation in type of alcoholic beverage, we could not study whether a specific type of beverage influenced hormonal levels and mammographic density more than others. However, the confounders did not differ by type of beverage.

Our study is the first, to our knowledge, to study associations between current and long-term alcohol consumption and endogenous cyclic premenopausal estrogen levels and mammographic density phenotypes. Studies consistently support a modest association between alcohol consumption and breast cancer risk [1-5], 
Table 3 Association between alcohol consumption by type of alcohol and mammographic density phenotypes in premenopausal women $(n=202)^{a}$ using multivariable linear regression models

\begin{tabular}{|c|c|c|c|c|}
\hline Alcohol consumption & Percent density $^{\mathrm{b}}(\%)$ & $p$-value & Absolute density ${ }^{\mathrm{b}}\left(\mathrm{cm}^{2}\right)$ & $p$-value \\
\hline \multicolumn{5}{|l|}{ Past year ${ }^{c}$} \\
\hline Total alcohol (drinks/week ${ }^{\mathrm{d}}$ ) & $0.72(0.23,1.22)$ & 0.004 & $1.28(0.52,2.03)$ & 0.001 \\
\hline Beer (drinks/week ${ }^{d}$ ) & $0.94(0.15,1.74)$ & 0.021 & $1.87(0.65,3.09)$ & 0.003 \\
\hline Wine (drinks/week ${ }^{d}$ ) & $2.02(0.62,3.41)$ & 0.005 & $2.84(0.66,5.01)$ & 0.011 \\
\hline Others $^{\mathrm{e}}$ (drinks/week ${ }^{\mathrm{d}}$ ) & $1.74(-0.23,3.70)$ & 0.084 & $3.17(0.13,6.21)$ & 0.041 \\
\hline \multicolumn{5}{|l|}{ Current, past week $^{f}$} \\
\hline Total alcohol (g/day) & $0.11(-0.12,0.34)$ & 0.362 & $0.26(-0.19,0.61)$ & 0.153 \\
\hline Beer (g/day) & $1.71(0.19,3.22)$ & 0.027 & $3.24(0.91,5.57)$ & 0.007 \\
\hline Wine (g/day) & $1.23(-0.30,2.75)$ & 0.113 & $1.90(-0.46,4.25)$ & 0.114 \\
\hline Others $^{\mathrm{e}}$ (g/day) & $-0.15(-1.93,1.62)$ & 0.865 & $-0.50(-3.25,2.26)$ & 0.723 \\
\hline
\end{tabular}

Data presented as $\beta$-value (95\% confidence interval). All analyses have used multivariable linear regression models, and are adjusted for age (continuous), body mass index (continuous), number of children (continuous), previous oral contraceptives (categorical), and current smokers (categorical)

FFQ food frequency questionnaire

a Numbers may vary owing to missing information

${ }^{\mathrm{b}}$ Estimated change in mammographic density per unit increase in the alcohol intake variable

cAlcohol consumption reported in past year, FFQ

${ }^{\mathrm{d} O n e}$ drink or unit is equal to $10 \mathrm{~g}$ alcohol

encludes spirits and fortified wine

${ }^{\mathrm{f}}$ Alcohol consumption reported in last 7 days representing 1 week, food diary

Table 4 Above-median percent (>28.5 \%) and absolute $\left(>32.4 \mathrm{~cm}^{2}\right)$ mammographic density according to past-year alcohol consumption by type in premenopausal women $(n=202)^{a}$

\begin{tabular}{|c|c|c|c|c|c|}
\hline \multirow[t]{2}{*}{ Alcohol consumption, past year ${ }^{b}$} & \multirow[b]{2}{*}{ Number } & \multicolumn{2}{|l|}{ Age-adjusted model $^{c}$} & \multicolumn{2}{|c|}{ Multivariable-adjusted model $^{d}$} \\
\hline & & Percent density (\%) & Absolute density $\left(\mathrm{cm}^{2}\right)$ & Percent density (\%) & Absolute density $\left(\mathrm{cm}^{2}\right)$ \\
\hline \multicolumn{6}{|l|}{ Total } \\
\hline$<1$ drink/week & 66 & 1.00 & 1.00 & 1.00 & 1.00 \\
\hline 1-6 drinks/week & 96 & $0.90(0.47,1.72)$ & $1.10(0.57,2.11)$ & $0.92(0.39,2.15)$ & $1.16(0.56,2.42)$ \\
\hline$\geq 7$ drinks/week & 40 & $2.37(1.00,5.60)$ & $4.38(1.76,10.87)$ & $2.78(0.90 .8 .60)$ & $5.08(1.82,14.20)$ \\
\hline$p$-trend & & 0.094 & 0.004 & 0.106 & 0.004 \\
\hline \multicolumn{6}{|l|}{ Beer } \\
\hline$<2$ drinks/week & 156 & 1.00 & 1.00 & 1.00 & 1.00 \\
\hline$\geq 2$ drinks/week & 45 & $1.33(0.66,2.67)$ & $1.96(0.97,3.98)$ & $1.25(0.51,3.03)$ & $1.95(0.90,4.24)$ \\
\hline p-difference & & 0.423 & 0.062 & 0.627 & 0.092 \\
\hline \multicolumn{6}{|l|}{ Wine } \\
\hline$<2$ drinks/week & 169 & 1.00 & 1.00 & 1.00 & 1.00 \\
\hline$\geq 2$ drinks/week & 33 & $2.18(0.97,4.93)$ & $2.60(1.14,5.93)$ & $2.06(0.77,5.53)$ & $2.47(1.03,5.92)$ \\
\hline$p$-difference & & 0.060 & 0.024 & 0.152 & 0.043 \\
\hline \multicolumn{6}{|l|}{ Others $^{e}$} \\
\hline$<2$ drinks/week & 184 & 1.00 & 1.00 & 1.00 & 1.00 \\
\hline$\geq 2$ drinks/week & 18 & $2.80(0.85,9.17)$ & $2.86(0.88,9.35)$ & $2.55(0.67,9.64)$ & $2.65(0.79,9.04)$ \\
\hline p-difference & & 0.090 & 0.081 & 0.196 & 0.119 \\
\hline
\end{tabular}

Data presented as odds ratio (95\% confidence interval). All analyses used multivariable logistic regression models

FFQ food frequency questionnaire

${ }^{a}$ Numbers may vary owing to missing information

${ }^{\mathrm{b}} \mathrm{Alcohol}$ consumption reported in past year, FFQ. One drink or unit is equal to $10 \mathrm{~g}$ alcohol

${ }^{\mathrm{c}}$ Adjusted for age (continuous)

${ }^{d}$ Adjusted for age (continuous), body mass index (continuous), number of children (continuous), previous oral contraceptives (categorical), and current smokers (categorical)

e Includes spirits and fortified wine 


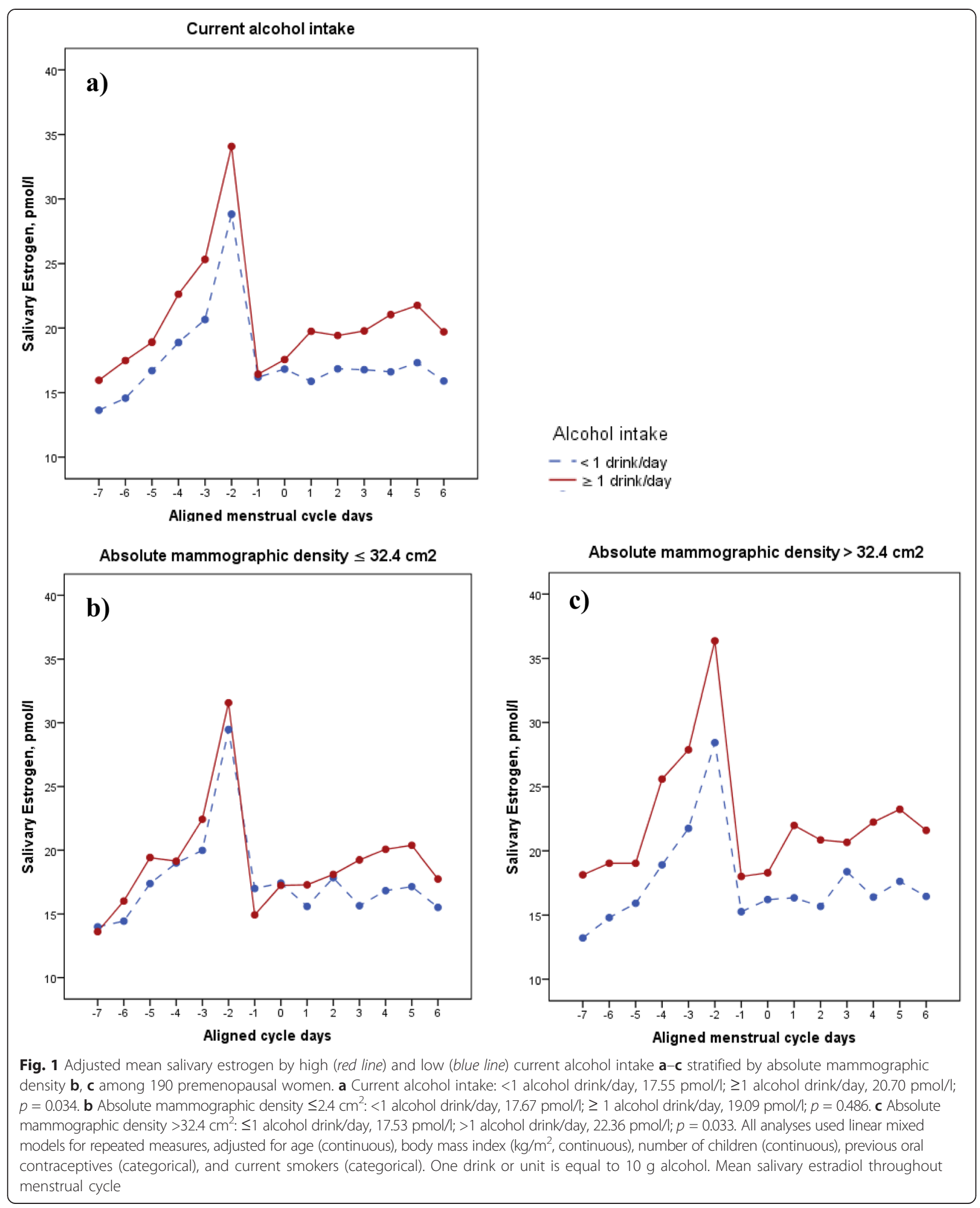

with a suggestive dose-response relationship [1]. One of the possible hypotheses suggested to explain the role of alcohol in breast cancer development is through alcohol's effect on the cumulative level of estrogen throughout life. However, inconsistent associations have been observed between alcohol and timed sampling of estrogens in the 
menstrual cycle [22]. Recently, a positive association between alcohol and luteal estrogen, but not between follicular estrogens, was observed [22]. These observations underline that additional studies are warranted to better understand the associations between alcohol and the $\mathrm{cu}-$ mulative level of estrogen throughout the menstrual cycle phase during premenopausal years. Alcohol consumption may act through increased aromatase activity [18], but other different biological mechanisms have been hypothesized [40, 41], supporting an association between endogenous estrogen and alcohol consumption. Interestingly, an association between endogenous estrogen and mammographic density has been observed [42-44]. The observed effect of high alcohol consumption on mammographic density may thus be explained by a direct effect of alcohol on breast density and/or an indirect effect through the estrogen pathway.

Previous studies report inconsistent results regarding the association between alcohol consumption during the past year and mammographic density phenotypes $[7,8,10,12,45]$. Few studies have examined the association between alcohol consumption and mammographic density in premenopausal women [12-14]. However, in some studies including both premenopausal and postmenopausal women, a positive association between alcohol consumption and qualitatively $[7,12]$ and quantitatively $[13,14]$ determined mammographic density was observed. Alcohol consumption over the past year reflects the cumulative alcohol consumption during 12 months, while current alcohol consumption assessed by our food diary reflects alcohol consumption during 1 week. The association observed in the present study between past-year alcohol consumption and mammographic density may thus be easier to observe compared with current alcohol consumption.

Interestingly, almost all of our observed associations were in relation to absolute mammographic density, also observed by others $[45,46]$. Absolute mammographic density reflects dense areas of the breast, mainly composed of epithelial and stromal tissues, while percent mammographic density reflects relative amounts of fibroglandular and fat tissue [42, 47, 48]. Importantly, the absolute dense area is considered to represent the actual target tissue for tumor development, as ductal carcinoma in situ and invasive breast cancer more often occur in dense areas [49-51].

To our knowledge, our study - in contrast to others [46]-includes long-term, past-year, and current alcohol consumption by type of alcohol and total consumption during 7 days of one menstrual cycle, in relation to mammographic density phenotypes. Our study thus combines several unique features because alcohol consumption was assessed among premenopausal women both by self-report combined with a supplementary interview using validated semi-quantitative FFQ [52] as well as a food diary [32].

Estrogen was assessed in both serum and saliva throughout an entire menstrual cycle, following strict procedures and validated methods [33]. This is the recommended approach, yet it is rarely achieved owing to its logistic complexity [24]. However, serum estradiol includes both the protein-bound fraction and the free fraction of the hormone, while salivary estradiol reflects free, biologically active estradiol levels [29]. Of note, we observed no correlations between serum and salivary hormones among the participants in total, which is consistent with the results of other studies [53], as a correlation between salivary and serum concentrations within the individual was observed but not in total. This may be explained by the fact that serum hormones is dependent on the binding protein capacity, which differs greatly among individuals. Moreover, the serum levels in one individual, assessed only on a few days during a menstrual cycle, cannot be predicted from salivary concentrations in others $[33,53]$. Exploratory non-invasive sampling of salivary hormones may thus provide novel insight into the associations between bioactive hormones, alcohol, and mammographic density in breast cancer research [53]. Of importance, the curves and salivary estrogen concentrations describing ovarian function in the presented EBBA-I study resemble those observed in other populations $[35,54]$.

Mammograms were obtained for study purposes justified by evaluation in ethical committees, during the late follicular phase (days 7-12 after first day of bleeding), avoiding possible variations in mammographic density during the menstrual cycle [55]. Thus, owing to safety concerns, we could only obtain one measure of mammographic density, and therefore could not measure density pattern changes over a menstrual cycle. The validated computer-assisted method used was read by one experienced blinded reader, and has previously been shown to give a superior prediction of breast cancer risk compared with qualitative methods $[37,56]$.

The present hypothesis-generating study also has some limitations. The small sample size limits further stratified analyses. However, our multiple salivary hormone variables are not considered to be independent measures, but indices within the same aligned menstrual cycle. Multiple corrections with Bonferroni for each variable would thus be too stringent. The assessment of daily salivary levels of unbound bioavailable estradiol throughout a menstrual cycle is unique, but there is a need for further studies because total serum hormones and free unbound salivary hormone levels are often correlated within individuals, while pooled data often show no significant correlations [33, 53]. Immunoassay methods used in the present study have most often been replaced 
recently by liquid chromatography-mass spectrometry, which compared with the immunoassay method is a more efficient way of analyzing salivary hormones with higher specificity and sensitivity. However, previous studies on estradiol measurements, specifically, have shown a high correlation between mass spectrometry and immunoassays [57]. The present study lasted for one menstrual cycle, and thus we were not able to capture any changes in estrogen levels between cycles. Alcohol consumption as assessed by a food diary was registered for 7 days (each day of a week represented), and captured binge versus daily consumption. The possibility to study daily variation for each cycle day was thus not possible. However, to minimize any information bias by day of the week or by cycle day, the current alcohol consumption was collected by a food diary for all seven unique days.

Given the increase in alcohol consumption among women worldwide [58], an association between alcohol consumption and breast cancer biomarkers, including endogenous estrogen levels and mammographic density, may have public health impact. If the association between alcohol use and mammographic density is determined to be causal, it could provide additional impetus for women to limit their alcohol consumption.

\section{Conclusion}

Alcohol consumption was positively associated with mammographic density phenotypes in premenopausal women. Higher levels of daily estrogen were observed among women with high current alcohol consumption and high mammographic density. Given that alcohol intake consistently has been observed to be associated with higher breast cancer risk, these positive associations observed between alcohol consumption, endogenous estrogen, and mammographic density could point to an important area of breast cancer prevention. However, the results need to be replicated in larger studies, assessing information of both current and long-term alcohol consumption.

\section{Additional file}

Additional file 1: Table S1. Presenting correlation between alcohol consumption assessed by FFQ and food diary $(n=202)$. (DOC $31 \mathrm{~kb}$ )

\section{Abbreviations \\ BMI: Body mass index; Cl: Confidence interval; CV: Coefficient of variation; EBBA-I: Norwegian Energy Balance and Breast Cancer Aspects I; FFQ: Food frequency questionnaires; OC: Oral contraceptive; ROI: Region of interest; UNN: University Hospital of North Norway.}

\section{Competing interests}

None of the authors have any financial relationship with the organizations that sponsored the research. The authors declare that they have no competing interests.

\section{Authors' contributions}

IT and A-SF conceived and designed the study, and collected clinical data. PTE carried out the radioimmunoassay and measured salivary hormone levels. GU digitized and measured the mammographic density data. HF, VGF, and TW performed statistical analyses. HF, VGF, ESB, A-SF, AM, TW, GU, PTE, $A H, G J$, and IT interpreted the results. HF drafted the manuscript in cooperation with IT. IML interpreted the results. All authors contributed with critical revision, editing of the final version of the manuscript, approved the final version for publication, and agree to be accountable for the accuracy and integrity of the work.

\section{Acknowledgements}

The authors acknowledge each woman who participated in the Norwegian EBBA-I study, our nurse Gunn Knudsen, Anna Kirsti Jenssen and Sissel Andersen. The study was supported by grant from the Norwegian Cancer Society (TP 49 257 and project number 05087), the Foundation for the Norwegian Health and Rehabilitation Organizations (59010-2000/2001/2002), and the Aakre Foundation (5695-200 and 5754-2002). The funders did not influence the conduct of the study, the preparation of this paper, or the decision to publish.

\section{Author details}

${ }^{1}$ The Cancer Centre, Oslo University Hospital, 0424 Oslo, Norway. ${ }^{2}$ Department of Obstetrics and Gynecology, University of Rochester School of Medicine and Dentistry, 601 Elmwood Avenue, Box 668, Rochester, NY 14534, USA. ${ }^{3}$ Department of Community Medicine, Faculty of Health Sciences, The Arctic University of Norway, 9037 Tromsø, Norway. ${ }^{4}$ Cancer Registry of Norway, PO Box 5313, Majorstuen 0304, Oslo, Norway. ${ }^{5}$ Department of Human Evolutionary Biology, Harvard University, Cambridge, MA 02138, USA. ${ }^{6}$ Fred Hutchinson Cancer Research Center, Seattle, WA 98109, USA. 7 Department of Nutrition, Institute of Basic Medical Sciences, University of Oslo, 0316 Oslo, Norway. ${ }^{8}$ Department of Environmental Health, Jagiellonian University Collegium Medicum, 31-531 Krakow, Poland.

Received: 17 April 2015 Accepted: 24 June 2015

Published online: 07 August 2015

\section{References}

1. Hamajima N, Hirose K, Tajima K, Rohan T, Calle EE, Heath Jr CW, et al. Alcohol, tobacco and breast cancer-collaborative reanalysis of individual data from 53 epidemiological studies, including 58,515 women with breast cancer and 95,067 women without the disease. Br J Cancer. 2002;87:1234-45.

2. Ellison RC, Zhang Y, McLennan CE, Rothman KJ. Exploring the relation of alcohol consumption to risk of breast cancer. Am J Epidemiol. 2001;154:740-7.

3. Morch LS, Johansen D, Thygesen LC, Tjonneland A, Lokkegaard E, Stahlberg C, et al. Alcohol drinking, consumption patterns and breast cancer among Danish nurses: a cohort study. Eur J Public Health. 2007;17:624-9.

4. Suzuki R, Orsini N, Mignone L, Saji S, Wolk A. Alcohol intake and risk of breast cancer defined by estrogen and progesterone receptor status-a meta-analysis of epidemiological studies. Int J Cancer. 2008;122:1832-41.

5. Key J, Hodgson S, Omar RZ, Jensen TK, Thompson SG, Boobis AR, et al. Meta-analysis of studies of alcohol and breast cancer with consideration of the methodological issues. Cancer Causes Control. 2006;17:759-70.

6. Boyd NF, Guo H, Martin LJ, Sun L, Stone J, Fishell E, et al. Mammographic density and the risk and detection of breast cancer. N Engl J Med. 2007;356:227-36.

7. Cabanes A, Pastor-Barriuso R, Garcia-Lopez M, Pedraz-Pingarron C, Sanchez-Contador C, Vazquez Carrete JA, et al. Alcohol, tobacco, and mammographic density: a population-based study. Breast Cancer Res Treat. 2011;129:135-47.

8. Maskarinec G, Takata Y, Pagano I, Lurie G, Wilkens LR, Kolonel LN. Alcohol consumption and mammographic density in a multiethnic population. Int J Cancer. 2006;118:2579-83.

9. Conroy SM, Koga K, Woolcott CG, Dahl T, Byrne C, Nagata C, et al. Higher alcohol intake may modify the association between mammographic density and breast cancer: an analysis of three case-control studies. Cancer Epidemiol. 2012;36:458-60.

10. Qureshi SA, Couto E, Hofvind S, Wu AH, Ursin G. Alcohol intake and mammographic density in postmenopausal Norwegian women. Breast Cancer Res Treat. 2012;131:993-1002. 
11. McDonald JA, Goyal A, Terry MB. Alcohol intake and breast cancer risk: weighing the overall evidence. Curr Breast Cancer Reports. 2013;5(3)208-21. doi:10.1007/s12609-013-0114-z.

12. Masala G, Ambrogetti D, Assedi M, Giorgi D, Del Turco MR, Palli D. Dietary and lifestyle determinants of mammographic breast density. A longitudinal study in a Mediterranean population. Int J Cancer. 2006:118:1782-9.

13. Vachon CM, Kuni CC, Anderson K, Anderson VE, Sellers TA. Association of mammographically defined percent breast density with epidemiologic risk factors for breast cancer (United States). Cancer Causes Control. 2000;11:653-62.

14. Yaghjyan L, Mahoney MC, Succop P, Wones R, Buckholz J, Pinney SM. Relationship between breast cancer risk factors and mammographic breast density in the Fernald Community Cohort. Br J Cancer. 2012;106:996-1003.

15. Key TJ, Appleby PN, Reeves GK, Travis RC, Alberg AJ, Barricarte A, et al. Sex hormones and risk of breast cancer in premenopausal women: a collaborative reanalysis of individual participant data from seven prospective studies. Lancet Oncol. 2013;14:1009-19.

16. Kaaks R, Rinaldi S, Key TJ, Berrino F, Peeters PH, Biessy C, et al. Postmenopausal serum androgens, oestrogens and breast cancer risk: the European prospective investigation into cancer and nutrition. Endocr Relat Cancer. 2005;12:1071-82.

17. Dumitrescu RG, Shields PG. The etiology of alcohol-induced breast cancer. Alcohol (Fayetteville, NY). 2005;35:213-25.

18. Castro GD, Castro JA. Alcohol drinking and mammary cancer: Pathogenesis and potential dietary preventive alternatives. World J Clin Oncol. 2014;5:713-29.

19. Suzuki R, Ye W, Rylander-Rudqvist T, Saji S, Colditz GA, Wolk A. Alcohol and postmenopausal breast cancer risk defined by estrogen and progesterone receptor status: a prospective cohort study. J Natl Cancer Inst. 2005;97:1601-8.

20. Cooper GS, Sandler DP, Whelan EA, Smith KR. Association of physical and behavioral characteristics with menstrual cycle patterns in women age 29-31 years. Epidemiology (Cambridge, Mass). 1996;7:624-8.

21. Reichman ME, Judd JT, Longcope C, Schatzkin A, Clevidence BA, Nair PP, et al. Effects of alcohol consumption on plasma and urinary hormone concentrations in premenopausal women. J Natl Cancer Inst. 1993;85:722-7.

22. Hirko KA, Spiegelman D, Willett WC, Hankinson SE, Eliassen AH. Alcohol consumption in relation to plasma sex hormones, prolactin and sex hormone-binding globulin in premenopausal women. Cancer Epidemiol Biomarkers Prev. 2014;23:2943-53.

23. Dorgan JF, Baer DJ, Albert PS, Judd JT, Brown ED, Corle DK, et al. Serum hormones and the alcohol-breast cancer association in postmenopausal women. J Natl Cancer Inst. 2001;93:710-5.

24. Bellem A, Meiyappan S, Romans S, Einstein G. Measuring estrogens and progestagens in humans: an overview of methods. Gend Med. 2011;8:283-99.

25. Jasienska G, Jasienski M. Interpopulation, interindividual, intercycle, and intracycle natural variation in progesterone levels: a quantitative assessment and implications for population studies. Am J Hum Biol. 2008;20:35-42.

26. Rinaldi S, Peeters PH, Bezemer ID, Dossus L, Biessy C, Sacerdote C, et al. Relationship of alcohol intake and sex steroid concentrations in blood in pre- and post-menopausal women: the European Prospective Investigation into Cancer and Nutrition. Cancer Causes Control. 2006;17:1033-43.

27. Frydenberg $H$, Flote VG, Iversen A, Finstad SE, Furberg AS, Torjesen PA, et al. Insulin-like growth factor-1, growth hormone, and daily cycling estrogen are associated with mammographic density in premenopausal women. Cancer Causes Control. 2014;25:891-903. doi:10.1007/s10552-014-0389-z.

28. Iversen A, Frydenberg H, Furberg AS, Flote VG, Finstad SE, McTiernan A, Ursin G, Wilsgaard T, Ellison PT, Jasienska G, et al. Cyclic endogenous estrogen and progesterone vary by mammographic density phenotypes in premenopausal women. Eur J Cancer Prev. 2015. doi:10.1097/ CEJ.0000000000000130 [Epub ahead of print]

29. Furberg AS, Jasienska G, Bjurstam N, Torjesen PA, Emaus A, Lipson SF, et al, Metabolic and hormonal profiles: HDL cholesterol as a plausible biomarker of breast cancer risk. The Norwegian EBBA Study. Cancer Epidemiol Biomarkers Prev. 2005;14:33-40.

30. Barrett ES, Thune I, Lipson SF, Furberg AS, Ellison PT. A factor analysis approach to examining relationships among ovarian steroid concentrations, gonadotrophin concentrations and menstrual cycle length characteristics in healthy, cycling women. Hum Reprod. 2013;28:801-11.
31. Emaus A, Espetvedt S, Veierod MB, Ballard-Barbash R, Furberg AS, Ellison PT, et al. 17-Beta-estradiol in relation to age at menarche and adult obesity in premenopausal women. Hum Reprod. 2008;23:919-27.

32. Lillegaard IT, Andersen LF. Validation of a pre-coded food diary with energy expenditure, comparison of under-reporters $\mathrm{V}$. acceptable reporters. $\mathrm{Br}$ J Nutr. 2005;94:998-1003.

33. Ellison PT, Lipson SF. Salivary estradiol—a viable alternative? Fertil Steril. 1999;72:951-2

34. Ellison PT, Panter-Brick C, Lipson SF, O'Rourke MT. The ecological context of human ovarian function. Hum Reprod. 1993;8:2248-58.

35. Lipson SF, Ellison PT. Comparison of salivary steroid profiles in naturally occurring conception and non-conception cycles. Hum Reprod. 1996;11:2090-6.

36. Bjurstam N, Bjorneld L, Warwick J, Sala E, Duffy SW, Nystrom L, et al. The Gothenburg Breast Screening Trial. Cancer. 2003;97:2387-96.

37. Ursin G, Astrahan MA, Salane M, Parisky YR, Pearce JG, Daniels JR, et al. The detection of changes in mammographic densities. Cancer Epidemiol Biomarkers Prev. 1998;7:43-7.

38. van Gils $\mathrm{CH}$, Hendriks JH, Otten JD, Holland R, Verbeek AL. Parity and mammographic breast density in relation to breast cancer risk: indication of interaction. Eur J Cancer Prev. 2000:9:105-11.

39. Yaghjyan L, Colditz GA, Rosner B, Tamimi RM. Mammographic breast density and subsequent risk of breast cancer in postmenopausal women according to the time since the mammogram. Cancer Epidemiol Biomarkers Prev. 2013;22:1110-7.

40. Secretan B, Straif K, Baan R, Grosse Y, El Ghissassi F, Bouvard V, et al. A review of human carcinogens-Part E: tobacco, areca nut, alcohol, coal smoke, and salted fish. Lancet Oncol. 2009;10:1033-4.

41. Wang $L$, Zhang $Y$, Ding D, He X, Zhu Z. Lack of association of ADH1C genotype with breast cancer susceptibility in Caucasian population: a pooled analysis of case-control studies. Breast (Edinburgh, Scotland). 2012;21:435-9.

42. Boyd NF, Martin LJ, Yaffe MJ, Minkin S. Mammographic density and breast cancer risk: current understanding and future prospects. Breast Cancer Res. 2011;13:223

43. Brower $\mathrm{V}$. Homing in on mechanisms linking breast density to breast cancer risk. J Natl Cancer Inst. 2010;102:843-5.

44. Yong M, Atkinson C, Newton KM, Aiello Bowles EJ, Stanczyk FZ, Westerlind KC, et al. Associations between endogenous sex hormone levels and mammographic and bone densities in premenopausal women. Cancer Causes Control. 2009;20:1039-53.

45. Brand JS, Czene K, Eriksson L, Trinh T, Bhoo-Pathy N, Hall P, et al. Influence of lifestyle factors on mammographic density in postmenopausal women. PLoS One. 2013;8, e81876.

46. Flom JD, Ferris JS, Tehranifar P, Terry MB. Alcohol intake over the life course and mammographic density. Breast Cancer Res Treat. 2009;117:643-51.

47. Stone J, Ding J, Warren RM, Duffy SW, Hopper JL. Using mammographic density to predict breast cancer risk: dense area or percentage dense area. Breast Cancer Res. 2010;12:R97.

48. Pettersson A, Hankinson SE, Willett WC, Lagiou P, Trichopoulos D, Tamimi RM. Nondense mammographic area and risk of breast cancer. Breast Cancer Res. 2011;13:R100.

49. Gill JK, Maskarinec G, Pagano I, Kolonel LN. The association of mammographic density with ductal carcinoma in situ of the breast: the Multiethnic Cohort. Breast Cancer Res. 2006:8:R30.

50. Pinto Pereira SM, McCormack VA, Hipwell JH, Record C, Wilkinson LS, Moss SM, et al. Localized fibroglandular tissue as a predictor of future tumor location within the breast. Cancer Epidemiol Biomarkers Prev. 2011;20:1718-25.

51. Ursin G, Hovanessian-Larsen L, Parisky YR, Pike MC, Wu AH. Greatly increased occurrence of breast cancers in areas of mammographically dense tissue. Breast Cancer Res. 2005;7:R605-8.

52. Jacobsen BK, Bonaa $\mathrm{KH}$. The reproducibility of dietary data from a selfadministered questionnaire. The Tromso Study. Int J Epidemiol. 1990;19:349-53.

53. Lu Y, Bentley GR, Gann PH, Hodges KR, Chatterton RT. Salivary estradiol and progesterone levels in conception and nonconception cycles in women: evaluation of a new assay for salivary estradiol. Fertil Steril. 1999;71:863-8.

54. Ziomkiewicz A, Ellison PT, Lipson SF, Thune I, Jasienska G. Body fat, energy balance and estradiol levels: a study based on hormonal profiles from complete menstrual cycles. Hum Reprod. 2008;23:2555-63. 
55. Morrow M, Chatterton Jr RT, Rademaker AW, Hou N, Jordan VC, Hendrick RE, et al. A prospective study of variability in mammographic density during the menstrual cycle. Breast Cancer Res Treat. 2010;121:565-74.

56. Boyd NF, Byng JW, Jong RA, Fishell EK, Little LE, Miller AB, et al. Quantitative classification of mammographic densities and breast cancer risk: results from the Canadian National Breast Screening Study. J Natl Cancer Inst. 1995;87:670-5

57. Holst JP, Soldin OP, Guo T, Soldin SJ. Steroid hormones: relevance and measurement in the clinical laboratory. Clin Lab Med. 2004;24:105-18.

58. WHO. Global status report on alcohol and health. 2014 http:// www.who.int/substance_abuse/publications/global_alcohol_report/ msb_gsr_2014_1.pdf?ua=1

\section{Submit your next manuscript to BioMed Central and take full advantage of:}

- Convenient online submission

- Thorough peer review

- No space constraints or color figure charges

- Immediate publication on acceptance

- Inclusion in PubMed, CAS, Scopus and Google Scholar

- Research which is freely available for redistribution 